\title{
Long-Term Memory Is Facilitated by cAMP Response Element- Binding Protein Overexpression in the Amygdala
}

\author{
Sheena A. Josselyn, ${ }^{1}$ Chanjun Shi, ${ }^{1}$ William A. Carlezon Jr, ${ }^{1,2}$ Rachael L. Neve, ${ }^{2}$ Eric J. Nestler, ${ }^{1}$ \\ Michael Davis ${ }^{1}$ \\ ${ }^{1}$ Department of Psychiatry, Yale University School of Medicine and Connecticut Mental Health Center, New Haven, \\ Connecticut 06508, and 2Department of Genetics, Harvard Medical School, McLean Hospital, Belmont, Massachusetts \\ 02178
}

\begin{abstract}
At least two temporally and mechanistically distinct forms of memory are conserved across many species: short-term memory that persists minutes to hours after training and long-term memory (LTM) that persists days or longer. In general, repeated training trials presented with intervening rest intervals (spaced training) is more effective than massed training (the same number of training trials presented with no or short intervening rest intervals) in producing LTM. LTM requires de novo protein synthesis, and cAMP response element-binding protein (CREB) may be one of the transcription factors regulating the synthesis of new proteins necessary for the formation of LTM. Here we show that rats given massed fear conditioning training show no
\end{abstract}

or weak LTM, as measured by fear-potentiated startle, compared with rats given the same amount of training but presented in a spaced manner. Increasing CREB levels specifically in the basolateral amygdala via viral vector-mediated gene transfer significantly increases LTM after massed fear training. The enhancing effect of CREB overexpression on LTM formation is shown to be specific in terms of biochemistry, anatomy, time course, and the training procedure used. These results suggest that CREB activity in the amygdala serves as a molecular switch for the formation of LTM in fear conditioning.

Key words: amygdala; CREB; memory; fear conditioning; viral vector; startle
In species ranging from Aplysia (Carew et al., 1972), Drosophila (Tully et al., 1994), Chasmagnathus crab (Freudenthal et al., 1998), mouse (Kogan et al., 1996), rat (Fanselow and Tighe, 1988; Barela, 1999), to human (Ebbinghaus, 1885), spaced training (training trials presented with intervening rest intervals) is more effective than massed training (the same number of training trials presented with no or short intervening rest intervals) in producing long-term memory (LTM) for a variety of tasks. Either massed or spaced training, however, produce robust short-term memory (STM). Furthermore, LTM, unlike STM, requires de novo protein synthesis (Davis and Squire, 1984).

Several lines of evidence suggest that cAMP response elementbinding protein (CREB) is one of the transcription factors regulating the synthesis of proteins necessary for the formation of LTM (Dash et al., 1990; Kaang et al., 1993; Bourtchouladze et al., 1994; Yin et al., 1994, 1995; Guzowski and McGaugh, 1997; Lamprecht et al., 1997; Impey et al., 1998a). CREB is part of a family of transcription factors, members of which activate or repress transcription (Foulkes et al., 1991; Molina et al., 1993; Sassone-Corsi, 1995; De Cesare et al., 1999). The effectiveness of

\footnotetext{
Received Oct. 11, 2000; revised Dec. 13, 2000; accepted Dec. 14, 2000.

This work was supported by Natural Sciences and Engineering Research Council of Canada and National Alliance for Research on Schizophrenia and Depression fellowships to S.A.J., National Institute of Mental Health Grants MH-57250 and MH-47840, Research Scientist Development Award MH-0004, a grant from the Air Force Office of Scientific Research, and the State of Connecticut to M.D. We thank Paul W. Frankland and Alcino J. Silva for thoughtful comments on a previous version of this manuscript.

Correspondence should be addressed to Sheena A. Josselyn, Department of Neurobiology, Brain Research Institute, Gonda Building Room 2554, 695 Young Drive South, University of California, Los Angeles Medical School, Los Angeles, CA 90095. E-mail: sjosselyn@mednet.ucla.edu.

Drs. Shi and Davis's present address: Department of Psychiatry, Emory University School of Medicine, 1639 Pierce Drive, Suite 4311, Atlanta, GA 30322.

Copyright (C) 2001 Society for Neuroscience $0270-6474 / 01 / 212404-09 \$ 15.00 / 0$
}

massed and spaced training schedules to produce maximal LTM may depend on the ratio of CREB isoforms such that spaced training may be required to produce maximal LTM when the levels of CREB activator isoforms are relatively low, whereas massed training alone may be sufficient to produce LTM when the levels of activator isoforms are higher (Yin et al., 1995). For example, overexpression of a CREB activator isoform in flies produces maximal LTM after massed training alone (Yin et al., 1995). Conversely, the LTM deficit observed in mutant mice lacking two major activator isoforms of CREB is "rescued" by training with spaced trials (Kogan et al., 1996).

In the fear-potentiated startle paradigm, memory (both STM and LTM) is inferred from an increase in the amplitude of the startle response of rats when the startle reflex is elicited in the presence of a light [the conditioned stimulus (CS)] that has been previously paired with footshock [the unconditioned stimulus (US)]. The neural circuitry underlying the acquisition of memory using conditioned fear paradigms is well characterized (Davis, 1992; Maren and Fanselow, 1996; LeDoux, 2000), thus allowing for the examination of the effects of manipulating CREB levels specifically in an area of the brain directly implicated in the formation of memory rather than in a more global, nonregionspecific manner as in previous studies. The basolateral complex of the amygdala, specifically the lateral and basolateral nuclei, is necessary for the acquisition of fear conditioning (LeDoux et al., 1990; Miserendino et al., 1990; Romanski et al., 1993; Campeau and Davis, 1995). Therefore, we examined the effects of increasing CREB levels specifically in the basolateral amygdala of rats using herpes simplex virus type 1 (HSV) vector-mediated gene transfer on memory produced by different schedules for fear training (massed or spaced). This technique of increasing CREB levels (Carlezon et al., 1998) provides both neural and temporal 
specificity that is currently not available in studies using mutant animals.

\section{MATERIALS AND METHODS}

\section{Animals}

Male albino Sprague Dawley rats (Charles River, Kingston, NY) weighing between 300 and $400 \mathrm{gm}$ were used. Rats were housed in groups of three to four in polyethylene cages and maintained in a $12 \mathrm{hr}$ light/dark cycle (lights on at 7:00 A.M.) with ad libitum access to food and water.

\section{Apparatus}

Rats were trained and tested in five identical Plexiglas and wire-mesh stabilimeters $(8 \times 15 \times 15 \mathrm{~cm})$ suspended between compression springs within a steel frame (Cassella and Davis, 1986). The floor of each stabilimeter consisted of four stainless steel bars $(6.0 \mathrm{~mm}$ in diameter) spaced $18 \mathrm{~mm}$ apart through which shock could be delivered. Stabilimeter movement resulted in displacement of an accelerometer located at the bottom of each stabilimeter, in which the resultant voltage was proportional to the velocity of cage displacement. The analog output of the accelerometer was amplified and digitized on a scale of 0-4096 units by a MacADIOS II board (GW Instruments, Somerville, MA) interfaced with an Apple Computers (Cupertino, CA) Macintosh II microcomputer. The stabilimeters were housed in a ventilated, dark, sound-attenuating chamber $(2.5 \times 2.5 \times 2 \mathrm{~m}$; Industrial Acoustics Co., Bronx, NY).

Background white noise $(0-20 \mathrm{kHz})$ of $55 \mathrm{~dB}$ sound pressure level was provided by a white noise generator (Layfayette 15800) delivered through a speaker (range of $0.02-20 \mathrm{kHz}$; Jamocar 70) located $70 \mathrm{~cm}$ in front of each stabilimeter. The startle-eliciting stimulus was a $105 \mathrm{~dB}, 50$ msec burst of white noise (rise-decay time of $5 \mathrm{msec}$ ), provided by a noise generator $(0-20 \mathrm{kHz}$; Lafayette 15800$)$ and delivered through high-frequency speakers (range of 5-40 kHz; Radio Shack Super Tweeter) located $10 \mathrm{~cm}$ behind each stabilimeter. Sound level measurements were made with a Brüel \& Kjær (Marlborough, MA) 4133 condenser microphone fitted to a Brüel \& Kjær 2235 sound level meter (A scale, random input). A $3.7 \mathrm{sec}$ light CS was generated by an $8 \mathrm{~W}$ fluorescent light bulb (100 $\mu \mathrm{sec}$ rise time; 800 foot lamberts intensity). Footshocks were produced by five shock generators (SGS-004; LeHigh Valley, Beltsville, MD) located outside the sound attenuating chamber. Shock intensity was measured with a $1 \mathrm{k} \Omega$ resistor across a differential channel of an oscilloscope in series with a $100 \mathrm{k} \Omega$ resistor connected between adjacent floor bars within each stabilimeter. Current was defined as the root mean square voltage across the $1 \mathrm{k} \Omega$ resistor where $\mathrm{mA}=0.707 \times 0.5 \times$ peak-to-peak voltage. According to this method, the shock intensity was 0.6 or $0.3 \mathrm{~mA}$ with a duration of $500 \mathrm{msec}$. The presentation and sequencing of all stimuli were controlled by a Macintosh II microcomputer. Startle amplitude was defined as the peak acceleration voltage that occurred during the first $200 \mathrm{msec}$ after the onset of the startle stimulus.

\section{General behavioral procedures}

Habituation. To habituate animals to the behavioral apparatus, rats were placed in the stabilimeters and 5 min later presented with 10 startle stimuli at each of 95,100 , and $105 \mathrm{~dB}$ intensities on each of $2 \mathrm{~d}$ before surgery and training. The three intensities of startle stimuli were presented in an irregular order with an interstimulus interval of $30 \mathrm{sec}$. This habituation procedure minimizes the level of subsequent conditioning to the context alone.

Training. For all experiments, training took place on a single day. Rats were placed in the stabilimeter and 5 min later presented with four light-shock pairings in which a $3.7 \mathrm{sec}$ light (CS) coterminated with a 0.5 sec shock (US, $0.6 \mathrm{~mA}$ unless otherwise specified). Five min after the final light-shock pairing, animals were returned to their home cages. In the first experiment, the intertrial interval (ITI) was varied. The ITI was defined as the time between the offset of the light on trial $n$ and the onset of the light on trial $n+1$. In subsequent experiments, massed training was defined as having an ITI of $10 \mathrm{sec}$, whereas spaced training was defined as having an ITI of $8 \mathrm{~min}$.

To determine the effects of viral infusions on footshock sensitivity (the unconditional response), the mean shock reactivity was assessed by the displacement of the cage in the $200 \mathrm{msec}$ period after each of the four footshocks on the training day.

LTM testing. Forty-eight hours after training, rats were placed in the stabilimeters and, 5 min later, received 30 startle-eliciting stimuli alone (with an interstimulus interval of $30 \mathrm{sec}$ ) to establish stable startle responding followed by an additional 60 startle-eliciting stimuli. Half of these startle-eliciting stimuli occurred $3.2 \mathrm{sec}$ after the onset of the 3.7 sec light ("light-noise trial") and half occurred in darkness ("noise-alone trial"). The order of the two trial types (light-noise and noise-alone) was irregular with the restriction that the same trial type could occur no more than twice in a row. Fear-potentiated startle difference scores, used as an index of LTM, were calculated for each animal by subtracting the mean startle amplitudes on the 30 noise-alone trials from the mean startle amplitudes on the 30 light-noise trials.

Virus preparation. CREB and a mutant form of CREB (mCREB) cDNAs (kindly provided by M. E. Greenberg, Harvard University, Boston, MA) and LacZ were inserted into the HSV amplicon HSV-PrpUC and packaged using the helper 5 dl1.2 (Lim et al., 1996; Carlezon et al., 1997, 1998; Neve et al., 1997; Neve and Lim, 1999). Virus was purified on a sucrose gradient, pelleted, and resuspended in $10 \%$ sucrose. The average titer of the recombinant virus stocks was $4.0 \times 10^{7}$ infectious $\mathrm{U} / \mathrm{ml}$ and was similar for HSV-CREB and HSV-mCREB. Transgene expression was regulated by the constitutive promoter for the HSV immediate-early gene IE $4 / 5$.

Surgery. Surgery was conducted $24-48 \mathrm{hr}$ after the second habituation session. Rats were pretreated with atropine sulfate $(0.4 \mathrm{mg} / \mathrm{kg}$, i.p. $)$, anesthetized with sodium pentobarbital $(60 \mathrm{mg} / \mathrm{kg}$, i.p.), and placed in a David Kopf Instruments (Tujunga, CA) stereotaxic instrument. The skin was retracted, and holes were drilled in the skull bilaterally above the target region. Inf usion coordinates were based on the rat atlas of Paxinos and Watson (1986). The coordinates for the lateral nucleus of the amygdala were as follows: anteroposterior (AP), $-2.8 \mathrm{~mm}$; mediolateral (ML), $\pm 5.2 \mathrm{~mm}$; and dorsoventral (DV), -8.5 below the surface of the skull. The coordinates for the caudate nucleus were as follows: AP, +0.2 $\mathrm{mm}$; ML, $\pm 3.0 \mathrm{~mm}$; and DV, $-6.0 \mathrm{~mm}$. Bilateral microinjections $(2 \mu \mathrm{l})$ of PBS or HSV vectors were delivered over 10 min through 30 gauge injection cannulas (Plastics One, Roanoke, VA) attached by polyethylene tubing to Hamilton microsyringes $(10 \mu \mathrm{l})$ mounted in an infusion pump (model 975; Harvard Instruments, South Natick, MA). Infusion cannulas were left in place an additional $10 \mathrm{~min}$ to ensure diffusion. Unless otherwise stated, rats were trained $3 \mathrm{~d}$ after surgery because this time point has been shown to be have the highest transgene expression using this HSV system (Lim et al., 1996; Carlezon et al., 1997, 1998; Neve et al., 1997). An additional eight rats were used for immunocytochemistry and similarly injected with HSV vectors, but behavior was not performed on these rats.

Histology and immunocytochemistry. The placement of the inf usions was determined with cresyl violet staining for all rats used for behavior. After the completion of the LTM or STM test, rats were overdosed with chloral hydrate and perfused with saline, followed by $4 \%$ paraformaldehyde in PBS. Brains were removed and stored in a solution of $30 \%$ sucrose-PBS for at least $2 \mathrm{~d}$. Sections $(60 \mu \mathrm{m})$ were cut through the infusion site on a freezing microtome and mounted on gelatin-coated slides. After drying, the slides were stained with cresyl violet, and the site of injection was evaluated under a microscope. Inclusion of rats in statistical analyses was based strictly on site of injection, without knowledge of the behavioral data of individual rats. Only those rats with bilateral placements in the basolateral complex of the amygdala or caudate nucleus were included in the amygdala and caudate groups, respectively.

Brains undergoing immunocytochemistry were treated similarly to above, and rats were perf used $3 \mathrm{~d}$ after surgery (at the time when training occurred). Immunocytochemistry was performed on free-floating coronal sections $(40 \mu \mathrm{m})$. Brains infused with HSV-LacZ were reacted for $\beta$-galactosidase and counterstained with neutral red (according to Lim et al., 1996; Carlezon et al., 1997, 1998; Neve et al., 1997). Briefly, sections were placed overnight in a solution comprised of potassium ferrocyanide, potassium ferricyanide, $\mathrm{MgCl}_{2}, \mathrm{PBS}$, and 5-bromo-4-chloro-3-indolyl- $\beta$ D-galactopyranosidase $(0.2 \mathrm{mg} / \mathrm{ml}$; Boehringer Mannheim, Indianapolis, IN). Analysis of CREB expression in brain inf used with HSV-CREB was conducted according to Carlezon et al. (1998). Briefly, sections were incubated with $\mathrm{H}_{2} \mathrm{O}_{2}$ and Triton $\mathrm{X}-100$, blocked with bovine serum albumin, normal goat serum, and Triton X-100, and incubated with CREB antibody (1:1000; Upstate Biotechnology, Lake Placid, NY) overnight. Sections were then incubated with biotinylated goat anti-rabbit IgG secondary antiserum (1:200; Vector Laboratories, Burlingame, CA) and avidin-biotin-peroxidase complex (ABC) reagent (Vector Laboratories). Immunoreactivity was visualized using a diaminobenzidine reaction. 


\section{Specific behavioral procedures}

Effect of ITI in training on subsequent LTM. We first assessed the effect of varying the ITI between four light-shock pairings on the level of LTM as measured by fear-potentiated startle. Groups of rats received four light-shock pairings with an ITI of $3 \mathrm{sec}, 5 \mathrm{sec}, 10 \mathrm{sec}, 15 \mathrm{sec}, 2 \mathrm{~min}$, or 8 min. Fear-potentiated startle (LTM) was assessed 48 hr later.

Effect of CREB overexpression in the amygdala on LTM formation after massed training. We next examined the effects of increasing CREB levels specifically in the basolateral complex of the amygdala on LTM produced by massed training (10 sec ITI), a protocol that normally induces weak or no LTM. To increase CREB levels, we microinjected HSV vectors encoding the CREB protein (HSV-CREB) before training. As a control, different groups of rats were similarly injected with PBS, HSV encoding a control protein (HSV-LacZ encoding $\beta$-galactosidase), and HSV encoding an inactive mutant form of CREB protein (HSV-mCREB). Phosphorylation of CREB at $\operatorname{Ser}^{133}$ activates the protein and leads to the transcription of genes containing CRE sequences in the upstream promoter region, whereas replacing this Ser with a nonphosphorylatable Ala residue abolishes this transcriptional activity (Gonzalez and Montminy, 1989; Ginty et al., 1992; Armstrong and Montminy, 1993). Thus, mCREB binds to the CRE site but is unable to regulate transcription, thereby creating an inactive CREB control.

To determine whether the basolateral complex of the amygdala is a key site, additional groups of rats received HSV-CREB injections into the caudate nucleus, an area that is not thought to be critically involved in LTM of fear-potentiated startle.

Effects of CREB overexpression in the amygdala on LTM formation after explicitly unpaired training. To evaluate whether the effects of overexpression of CREB were specific to learning in that they required paired presentations of the light-shock during training, groups of rats received explicitly unpaired massed training in which presentation of the CS did not predict the US. Massed presentations of the light (four, ITI of $10 \mathrm{sec}$ ) were followed 4 min later by massed presentations of the shock (four, ITI of $10 \mathrm{sec}$ ). Three different treatment groups were used: (1) unoperated control, (2) infusion of PBS into the amygdala, or (3) infusion of HSV-CREB into the amygdala. Fear-potentiated startle testing occurred $48 \mathrm{hr}$ after training.

Effect of CREB overexpression before training or testing. Previous studies using similar HSV vectors with various transgenes driven by the HSV IE $4 / 5$ promoter show that expression of the transgene is maximal 2-4 d after infusion and diminishes thereafter (Lim et al., 1996; Carlezon et al., 1997, 1998; Neve et al., 1997). We took advantage of this temporal dynamic to assess the effect of CREB overexpression on formation versus expression of LTM. We compared the LTM produced by massed training in rats infused with HSV-CREB into the basolateral complex of the amygdala at different time points before training: (1) $3 \mathrm{~d}$ before training such that training occurred at a time of maximal CREB overexpression or (2) $14 \mathrm{~d}$ before training such that training occurred at a time of minimal CREB overexpression. Two groups of rats were given massed fear training (ITI of $10 \mathrm{sec}$ ) $3 \mathrm{~d}$ after HSV-CREB or HSV-LacZ inf usion into the basolateral amygdala ("3d HSV-CREB," and "3d HSV-LacZ," respectively), tested for LTM $48 \mathrm{hr}$ later (as in the previous experiments) and given a second LTM test (the same as the first LTM test) $14 \mathrm{~d}$ after HSV infusion. A third group ("14d HSV-CREB") received massed training $14 \mathrm{~d}$ after infusion of HSV-CREB and tested for LTM $48 \mathrm{hr}$ after training. Using this protocol, the $3 \mathrm{~d}$ groups (3d HSV-CREB and $3 \mathrm{~d}$ HSV-LacZ) were trained when transgene expression was high and (re)tested for LTM when transgene expression was low, whereas the $14 \mathrm{~d}$ group (14d HSV-CREB) was trained and tested when transgene expression was low. In addition, six rats were infused with HSV-LacZ and perfused either 3 or $14 \mathrm{~d}$ after surgery for immunocytochemical examination.

Effect of CREB overexpression in the amygdala on LTM after spaced training. To assess the effect of CREB overexpression on LTM produced by spaced training, we again separated the four light-shock pairings by an ITI of $8 \mathrm{~min}$. Groups of rats were trained with either a $0.6 \mathrm{~mA}$ shock or a $0.3 \mathrm{~mA}$ shock $3 \mathrm{~d}$ after intra-amygdala inf usion of PBS, HSV-CREB, or nothing (unoperated control animals) and tested for fear-potentiated startle $48 \mathrm{hr}$ after training.

Effects of CREB overexpression in the amygdala on STM after massed training. Previous studies indicate that STM, unlike LTM, is not dependent on CREB-mediated transcription (Bourtchouladze et al., 1994; Yin et al., 1994; Kogan et al., 1996; Lamprecht et al., 1997), although it has been reported that CREB1c, a cytoplasmic protein, modulates both short- and long-term facilitation in Aplysia (Bartsch et al., 1998). There-

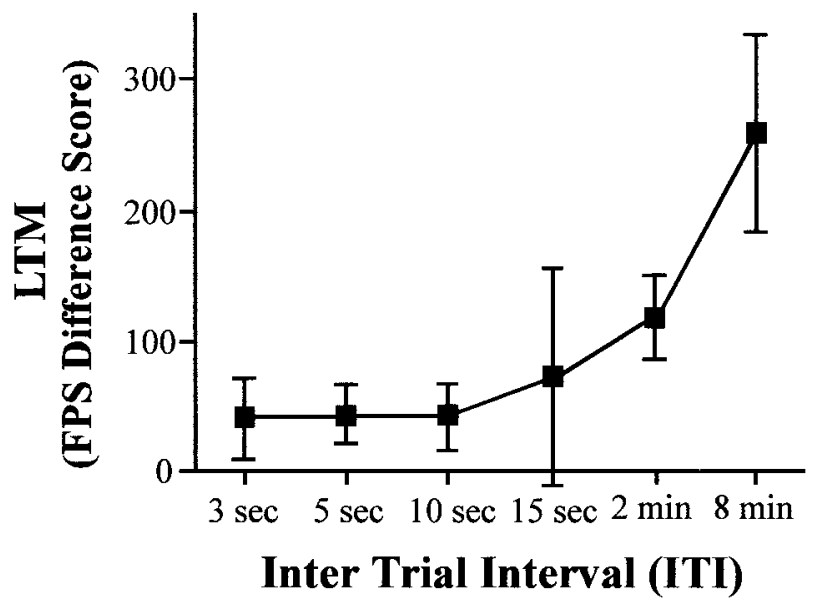

Figure 1. Effect of ITI on LTM as assessed by fear-potentiated startle. Fear-potentiated startle (FPS) difference scores were calculated by subtracting the mean startle amplitudes obtained on noise-alone trials from the mean startle amplitudes obtained on light-noise trials and used as an index of LTM. The mean \pm SEM level of LTM is shown after training, which consisted of four light-shock pairings with ITIs of $3 \mathrm{sec}, 5 \mathrm{sec}, 10$ sec, $15 \mathrm{sec}, 2 \mathrm{~min}$, and $8 \mathrm{~min}$. Massed training (10 sec and less) produced very weak LTM ( $\sim 50$ units), whereas spaced training $(8 \mathrm{~min})$ produced robust LTM.

fore, we examined the effects of CREB overexpression in the basolateral complex of the amygdala on STM produced by massed fear conditioning. STM testing was conducted similarly to LTM testing except that it occurred 15 or 40 min after massed (paired or unpaired) training. In groups in which the STM test was conducted 15 min after training, the animals were not removed from the stabilimeters, whereas in groups in which the STM test was conducted 40 min after training, animals were returned to the home cage for this delay. In the STM test, twenty noise-alone stimuli were followed by 15 light-noise stimuli and 15 noisealone stimuli presented in an irregular order. Fear-potentiated startle difference scores were calculated by subtracting the mean noise-alone score from mean light-noise score and used as an index of STM.

Groups of rats (unoperated control rats that received unpaired massed presentation of the light and shock or rats receiving intra-amygdala infusions of PBS or HSV-CREB before paired massed training) were tested for STM 15 min after training. Additional groups of rats (rats receiving intra-amygdala infusions of PBS, HSV-LacZ, or HSV-CREB) were tested for STM 40 min after massed training. In addition, a separate group of rats (rats receiving intra-amygdala infusions of PBS or HSVCREB) were given a STM test 40 min after massed training with a lower intensity of footshock $(0.3 \mathrm{~mA})$.

\section{RESULTS}

\section{Effect of ITI in training on subsequent LTM}

Figure 1 shows the LTM (fear-potentiated startle difference scores) for rats that received four light-shock pairings separated by different ITIs. Increasing ITIs produced greater LTM as assessed $48 \mathrm{hr}$ after training (Fig. 1); robust LTM was observed after spaced training ( 8 min ITI), whereas weak or no LTM was observed after massed training (3, 5, and $10 \mathrm{sec}$ ITIs). An ANOVA with between-group factor ITI $(3 \mathrm{sec}, 5 \mathrm{sec}, 10 \mathrm{sec}, 15$ sec, $2 \mathrm{~min}$, and $8 \mathrm{~min}$ ) was performed on the fear-potentiated startle difference scores from each group $(n=10,10,10,5,5$, and 15, respectively). The ANOVA showed a significant effect of ITI $\left(F_{(5,49)}=3.04 ; p<0.05\right)$, and post hoc Newman-Keuls test indicated that the LTM produced by the 8 min ITI was significantly greater than that produced by ITIs of $3,5,10$, or $15 \mathrm{sec}$. Therefore, consistent with previous results using a variety of species and different learning paradigms (Ebbinghaus, 1885; 

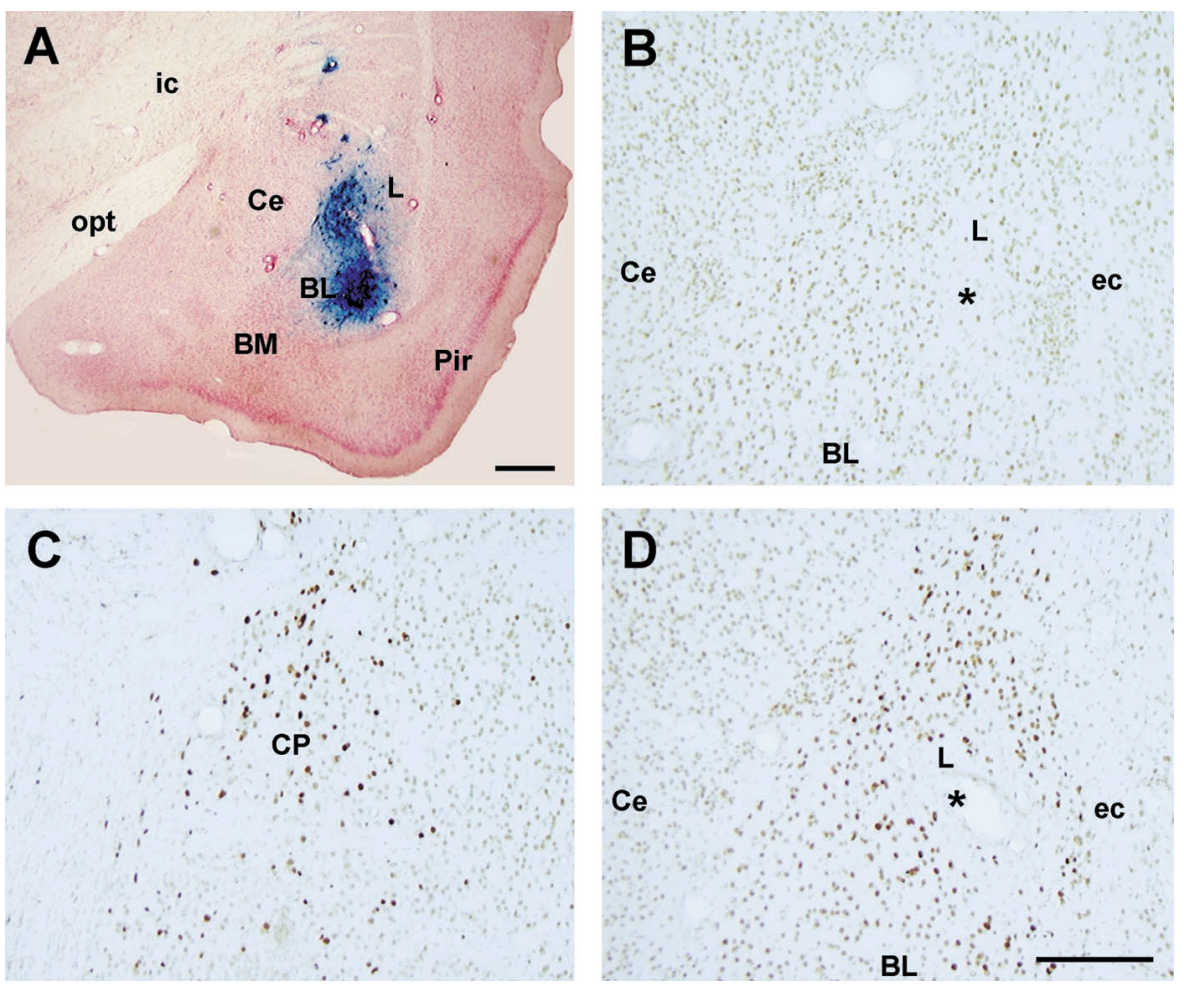

Figure 2. Immunocytochemical examination of the basolateral complex of the amygdala and caudate nucleus after infusion of HSV vectors. $A$, Expression of LacZ $3 \mathrm{~d}$ after infusion of HSV-LacZ into the basolateral amygdala. Sections are counterstained with neutral red and presented at low magnification. $B$, Expression of CREB $3 \mathrm{~d}$ after control infusion of HSV-LacZ into the basolateral amygdala. $C$, Overexpression of CREB $3 \mathrm{~d}$ after inf usion of HSV-CREB into the caudate nucleus. $D$, Overexpression of CREB $3 \mathrm{~d}$ after inf usion of HSV-CREB into the basolateral amygdala. * indicates location of infusion. $i c$, Internal capsule; opt, optic tract; $C e$, central nucleus of the amygdala; $L$, lateral nucleus of the amygdala; $B L$, basolateral nucleus of the amygdala; $B M$, basomedial nucleus of the amygdala; Pir, pyriform cortex; $e c$, external capsule; $C P$, caudate putamen. Scale bars, 0.2 mm.

Carew et al., 1972; Fanselow and Tighe, 1988; Tully et al., 1994; Freudenthal et al., 1998), massed training produces little or no LTM as measured by fear-potentiated startle, whereas spaced training produces robust LTM. Because the level of LTM produced by an ITI of $8 \mathrm{~min}$ was significantly greater than that produced by an ITI of $10 \mathrm{sec}$, these ITIs were chosen as examples of spaced and massed training, respectively, in additional studies.

\section{Effect of CREB overexpression in the amygdala on the LTM formation after massed training}

Infusion of HSV vectors produces high expression of the transgene

Figure 2 shows the immunocytochemical examination of representative brains performed $3 \mathrm{~d}$ after infusion of HSV vectors (when fear training normally occurred). HSV-LacZ (Fig. $2 A$ ) and HSV-CREB (Fig. $2 D$ ) infusion produced strong localized transgene expression throughout the basolateral complex of the amygdala (specifically, the lateral nucleus). Figure $2 A$ shows an area of $\beta$-galactosidase-positive cells surrounding the injection site of HSV-LacZ. The spread of positively stained cells was $\sim 1.5 \mathrm{~mm}^{2}$ from the injection tip. Similarly, infusion of HSV-CREB produced strong CREB immunostaining throughout the lateral nucleus of the amygdala but not in the central nucleus of the amygdala (Fig. 2D, Ce). This robust increase in CREB immunostaining is evident by comparing the light level of CREB immunostaining observed after infusion of HSV-LacZ into the basolateral amygdala (Fig. $2 B$ ) with the dark CREB immunostaining produced by infusion of HSV-CREB into the basolateral amygdala (Fig. 2D). It is important to note that these sections were treated identically [as shown by the similar light levels of CREB background staining in the central nucleus of the amygdala (Fig. $2 B, D, C e)]$. Similarly, infusion of HSV-CREB into the caudate nucleus produced strong CREB immunostaining (Fig. 2C). This finding that infusion of HSV-CREB strongly increases CREB immunostaining is in agreement with Carlezon et al. (1998). The number of neurons overexpressing CREB is likely underestimated in this preparation because the immunocytochemical conditions were adjusted so as to be minimally sensitive to the background (endogenous) levels of CREB.

Infusion of HSV vectors was accompanied by minimal tissue damage, similar to that produced by infusion of PBS, as assessed by cresyl violet staining. It is important to note that injection of HSV vectors produced no apparent behavioral abnormalities.

\section{Histology and site of infusion}

Histological examination of the infusion site in all animals tested for LTM showed that 17 of the rats infused with HSV-CREB had accurate bilateral infusion sites in the basolateral complex of the amygdala, most often within the lateral nucleus of the amygdala. The infusions of an additional eight rats infused with HSVCREB were improperly placed and, therefore, designated as extra-amygdala HSV-CREB. Of the rats infused with PBS, HSVLacZ, or HSV-mCREB, 7, 10, and 11, respectively, had accurate bilateral placements within the basolateral complex of the amygdala and were included in statistical analyses. Five rats infused with HSV-CREB directly into the caudate nucleus had accurate placements. 


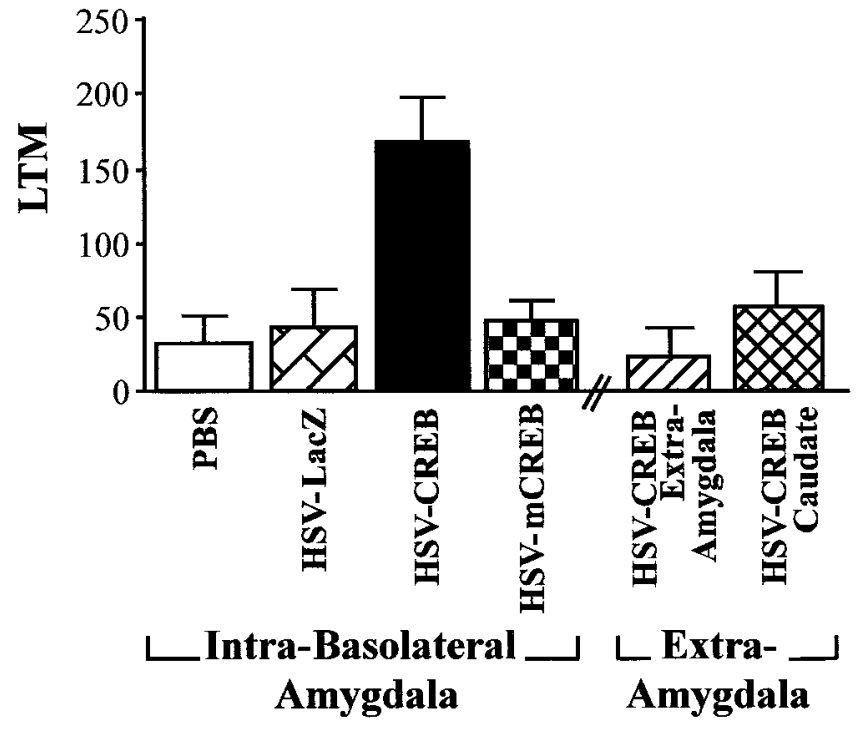

Figure 3. Effect of infusion of HSV vectors into the basolateral amygdala and extra-amygdala areas on the subsequent LTM (mean \pm SEM) observed $48 \mathrm{hr}$ after massed fear conditioning training (10 sec ITI). HSV vectors and PBS infusions were aimed at the basolateral amygdala and a control region (the caudate nucleus). However, several infusions of HSVCREB missed the amygdala target region and are thus designated as extra-amygdala (HSV-CREB Extra-Amygdala). Rats infused with HSVCREB into the basolateral amygdala showed significantly greater LTM than rats similarly inf used with PBS, HSV-LacZ, or HSV-mCREB or rats infused with HSV-CREB into brain regions surrounding the amygdala or directly into the caudate nucleus.

\section{Overexpression of CREB in the amygdala facilitates LTM} formation after massed training

Figure 3 shows the LTM scores from rats that received massed fear conditioning $3 \mathrm{~d}$ after infusion of PBS, HSV-CREB, or HSV-mCREB into the basolateral amygdala or HSV-CREB into the sites surrounding the amygdala or directly into the caudate nucleus. Remarkably, the weak LTM normally produced by massed training was strongly enhanced by infusion of HSVCREB into the amygdala. An ANOVA performed on the LTM scores with between-group factor treatment (intra-amygdala injections of PBS, HSV-LacZ, HSV-CREB, and HSV-mCREB, extra-amygdala injection of HSV-CREB, and intracaudate injection of HSV-CREB) showed a significant effect of treatment $\left(F_{(5,52)}=4.99 ; p<0.001\right)$, and a post hoc Newman-Keuls test indicated that rats infused with HSV-CREB into the basolateral amygdala exhibited significantly greater LTM than rats similarly infused with PBS, HSV-LacZ, or HSV-mCREB or rats infused with HSV-CREB into extra-amygdala sites or directly into the caudate nucleus. Importantly, neither control infusions of PBS, HSV-LacZ, or HSV-mCREB into the basolateral complex of the amygdala nor extra-amygdala or caudate infusion of HSV-CREB affected the weak LTM normally observed after massed training.

Figure $4 A$ shows that the mean shock reactivity during massed fear training for animals (from above) inf used with HSV vectors (PBS, HSV-LacZ, HSV-CREB, and HSV-mCREB) into the basolateral amygdala did not appear to differ. This observation was confirmed by the results of an ANOVA showing no significant effect of treatment $\left(F_{(3,41)}=1.41 ; p>0.05\right)$. However, as shown in Figure 3, animals infused with HSV-CREB subsequently showed increased LTM. This finding indicates that CREB overexpression did not facilitate LTM after massed training by increasing the salience of the US during training.

\section{Effects of CREB overexpression in the amygdala on LTM formation after explicitly unpaired training}

Figure $4 B$ shows the LTM (fear-potentiated startle difference scores) for unoperated control rats $(n=10)$ and rats that were inf used with PBS $(n=5)$ or HSV-CREB $(n=5)$ before unpaired massed training. As expected, unpaired massed training did not produce LTM for the light-shock association in unoperated control rats, and this was not altered by infusion of PBS or HSVCREB into the basolateral amygdala $\left(F_{(2,17)}=0.44 ; p>0.05\right)$. This finding indicates that the increase in LTM observed in animals given massed training after HSV-CREB inf usion into the basolateral amygdala (Fig. 3) critically depends on pairing the CS with the US.

\section{Effect of CREB overexpression before training or testing Immunocytochemistry: 3 versus $14 d$ after infusion}

Figure 5 shows the $\beta$-galactosidase staining from similarly treated brains 3 (Fig. 5A) and 14 (Fig. 5B) d after infusion of HSV-LacZ. In agreement with previous studies (Lim et al., 1996; Carlezon et al., 1997, 1998; Neve et al., 1997), the strong staining for the transgene observed $3 \mathrm{~d}$ after HSV inf usion was not observed $14 \mathrm{~d}$ after infusion. Similar results were obtained after infusion of HSV-CREB.

\section{Overexpression of CREB facilitates LTM formation rather than expression}

Figure $4 C$ shows the LTM scores for all groups inf used with HSV vectors (3d HSV-CREB, $n=10$; 3d HSV-LacZ, $n=3$; 14d HSV-CREB, $n=4)$. Rats from the $3 \mathrm{~d}$ HSV-CREB group showed greater LTM (on the second test conducted $14 \mathrm{~d}$ after HSV infusion) than similarly treated rats infused with HSV-LacZ (3d HSV-LacZ) or rats from the 14d HSV-CREB group. An ANOVA showed a significant effect of treatment $\left(F_{(2,14)}=6.05 ; p<0.05\right)$, and a post hoc test indicated that the 3d HSV-CREB group exhibited significantly greater LTM than either the 3d HSV-LacZ or 14d HSV-CREB groups. This result replicates our previous finding that overexpression of CREB in the amygdala facilitates LTM after massed training, even when retested several days later. Furthermore, these data indicate that massed training is sufficient to produce strong LTM only if training, rather than testing, is conducted when CREB level in the amygdala are high, thereby implicating LTM encoding rather than retrieval processes.

\section{Effect of CREB overexpression in the amygdala on LTM after spaced training}

Figure $6 A$ shows the LTM observed in unoperated control rats $(n=10)$ or rats receiving intra-amygdala infusions of PBS $(n=$ 17) or HSV-CREB $(n=8)$ after spaced fear conditioning training. Spaced training produces robust LTM in unoperated control rats, but intra-amygdala infusions of PBS or HSV-CREB did not further increase this $\left(F_{(2,27)}=0.21 ; p>0.05\right)$. One interpretation of the lack of effect of CREB overexpression on LTM produced by spaced training could be that increasing CREB in the amygdala facilitates the formation of LTM after relatively weak (for instance, massed) but not strong (spaced) training, or it may be that spaced training produced maximal LTM such that a possible enhancement by CREB overexpression may have been masked. To examine these alternatives, we conducted the same experiment but lowered the LTM ceiling by using a weaker intensity of shock ( 0.3 rather than $0.6 \mathrm{~mA})$. Figure $6 B$ shows the LTM scores produced by a separate group of rats [unoperated control rats $(n=10)$ or rats receiving intra-amygdala infusions of PBS $(n=$ 
A

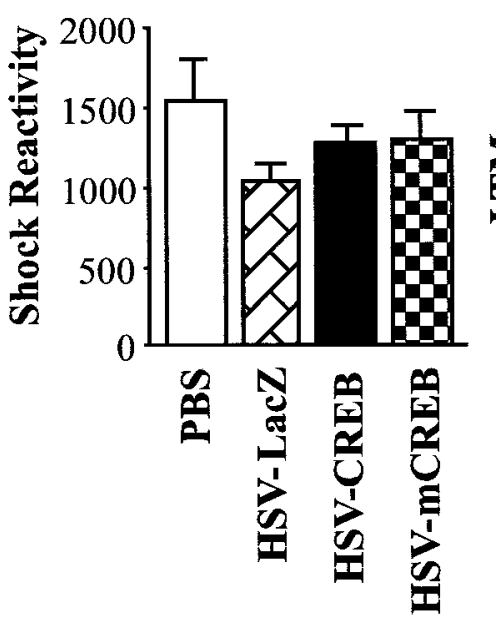

B

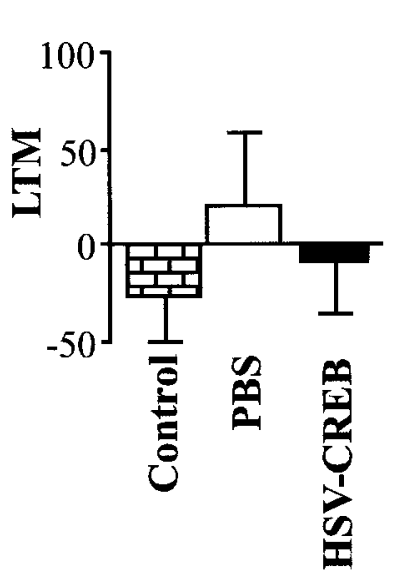

C

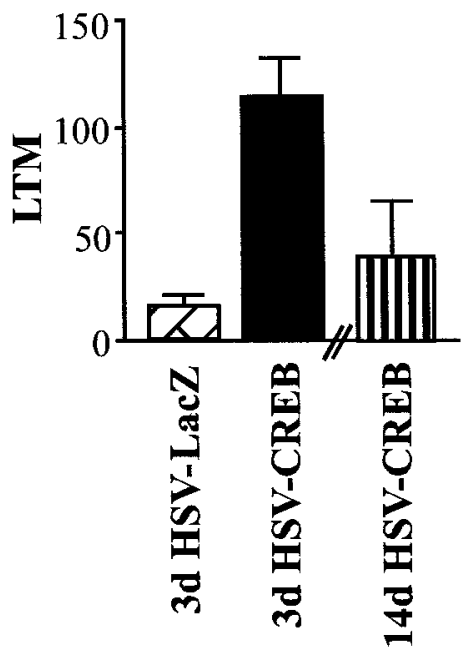

Figure 4. Specificity of the LTM-enhancing effects of CREB overexpression in the amygdala on LTM formation after massed training (10 sec ITI). A, Similar reactions to footshock were observed during training in rats infused with PBS, HSV-LacZ, HSV-CREB, or HSV-mCREB into the basolateral amygdala. $B$, Effects of HSV vectors on explicitly unpaired massed training. Explicitly unpaired conditioning fails to produce LTM in unoperated control rats. Furthermore, intrabasolateral amygdala inf usion of PBS or HSV-CREB does not enhance LTM after unpaired massed training. $C$, Time course of the effect of HSV vectors on LTM formation after massed training. Animals that received HSV-CREB $3 \mathrm{~d}$ before massed training show greater LTM when retested $14 \mathrm{~d}$ after infusion than animals similarly treated with HSV-LacZ or animals given HSV-CREB $14 \mathrm{~d}$ before massed training and tested $48 \mathrm{hr}$ later.

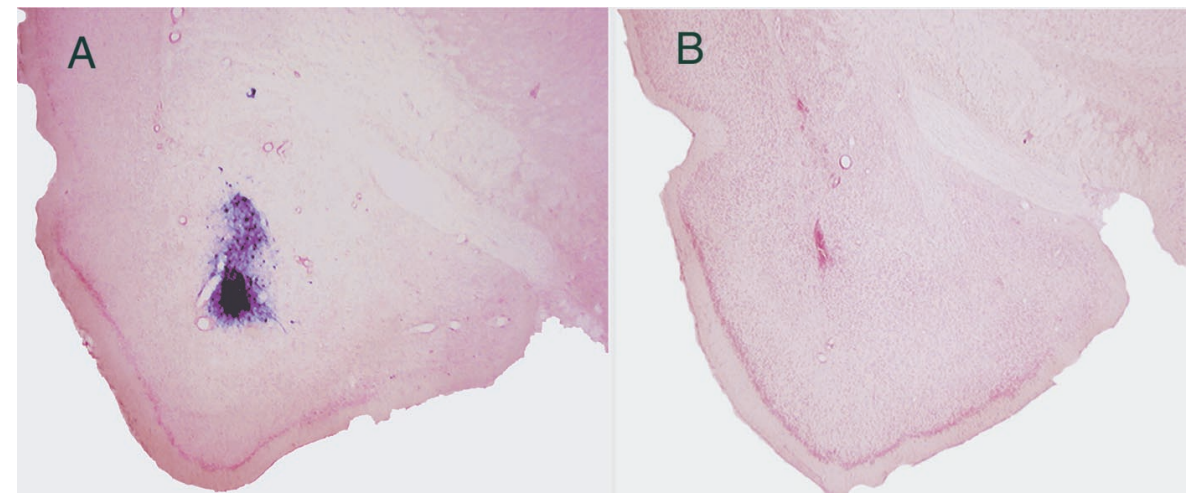

Figure 5. Time course of transgene expression after infusion of HSV-LacZ. A, High expression of the LacZ $3 \mathrm{~d}$ after inf usion of HSV-LacZ into the basolateral amygdala. Sections are counterstained with neutral red and presented at low magnification. $B$, Low expression of the LacZ transgene $14 \mathrm{~d}$ after infusion of HSV-LacZ into the basolateral amygdala.

16) or HSV-CREB $(n=7)]$ that were given a similar spaced training protocol (8 min ITI) with a weaker intensity of shock $(0.3$ rather than $0.6 \mathrm{~mA})$. Although spaced training using the lower shock intensity produced quantitatively less LTM relative to that produced by the higher shock intensity, there was no enhancement by HSV-CREB infusion $\left(F_{(2,30)}=0.90 ; p>0.05\right)$. Therefore, CREB overexpression does not simply enhance the low levels of LTM produced by all forms of weak conditioning, because the enhancement of LTM seem to be specific to massed training.

\section{Effects of CREB overexpression in the amygdala on STM after massed training}

Figure 7 shows the fear-potentiated startle difference scores as a measure of STM for unoperated control rats receiving unpaired massed training (in which the light did not predict the footshock; $n=5$ ), as well as rats infused with PBS or HSV-CREB into the basolateral complex of the amygdala ( $n=12$ and 11, respectively) that received massed training. As expected, unoperated control rats receiving unpaired massed training showed little evidence of STM tested 15 min after training compared with rats that received paired massed training $\left(F_{(1,15)}=5.09 ; p<0.05\right)$. This indicates that, although massed training is not sufficient to induce strong LTM, this deficit cannot be attributed to the animals not acquiring the association, because robust STM is observed. Infusion of HSV-CREB before massed training did not significantly change the level of STM from that observed in rats infused with $\operatorname{PBS}\left(F_{(1,21)}=0.001 ; p>0.05\right)$.

To mimic more closely the conditions of our previous LTM experiment in which animals are returned to the home cage between massed training and testing, we tested additional groups of rats $40 \mathrm{~min}$ after training. In this experiment, $\operatorname{PBS}(n=5)$, HSV-LacZ $(n=5)$, or HSV-CREB $(n=5)$ was infused before massed training and (delayed, $40 \mathrm{~min}$ ) STM testing. Again, infusion of HSV-CREB had no effect on the level of (delayed) STM 
$\mathbf{A}$

\section{$0.6 \mathrm{~mA}$}

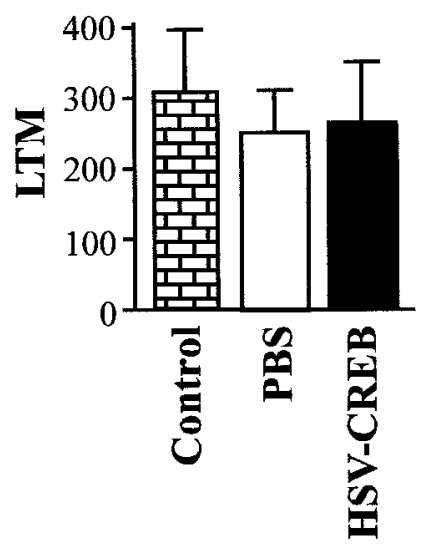

B

\section{$0.3 \mathrm{~mA}$}

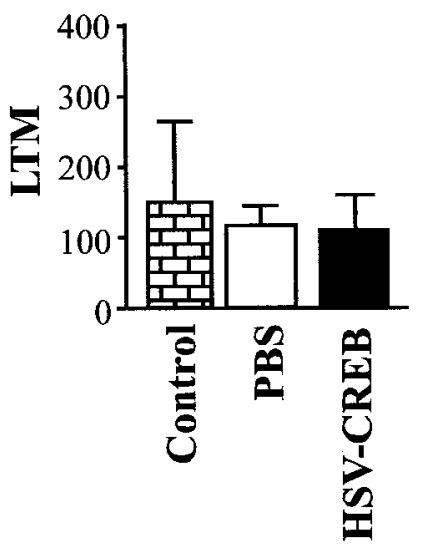

Figure 6. LTM after spaced (8 min ITI) training using different intensities of footshock after infusion of HSV vectors into the basolateral amygdala. $A$, High-footshock intensity $(0.6 \mathrm{~mA})$. The high levels of LTM $48 \mathrm{hr}$ after spaced training were not significantly different in control (unoperated) rats and those receiving PBS or HSV-CREB into the basolateral amygdala. $B$, Low-footshock intensity $(0.3 \mathrm{~mA})$. The modest levels of LTM were not significantly different in control (unoperated) rats and those receiving infusions of PBS or HSV-CREB into the basolateral amygdala. The higher footshock intensity $(0.6 \mathrm{~mA})$ produced significantly greater LTM that did the weaker footshock intensity $(0.3 \mathrm{~mA})$, but increasing CREB levels did not change this.

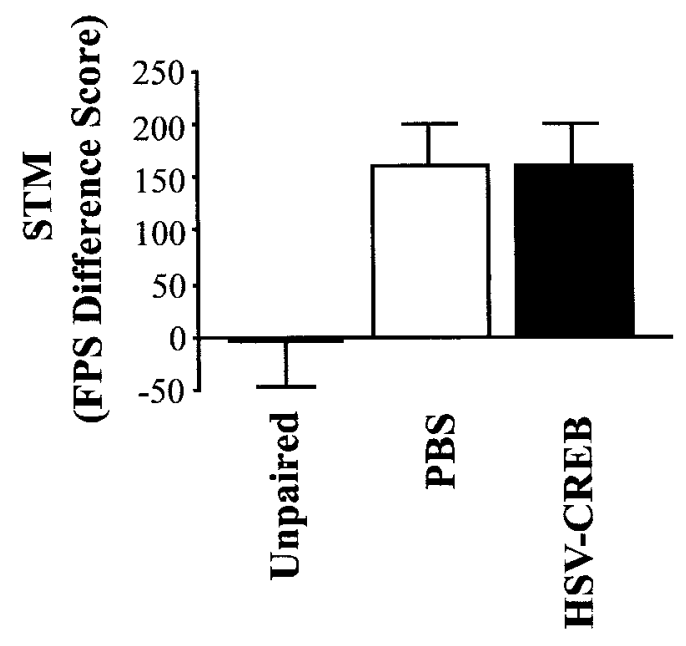

Figure 7. STM, as measured by fear-potentiated startle (FPS) difference scores, after massed training in animals inf used with HSV vectors in the basolateral amygdala. Control rats that received unpaired massed presentation of the light and shock show less STM than rats that had received inf usion of PBS and paired massed training. However, rats infused with HSV-CREB did not differ in STM levels from rats infused with PBS.

$\left(F_{(2,12)}=0.94 ; p>0.05\right.$; data not shown). Repeating this experiment with a lower shock intensity ( $0.3 \mathrm{~mA}$ shock) also showed no difference between rats infused with PBS $(n=5)$ or HSV-CREB $(n=5)$ and tested for (delayed) $\operatorname{STM}\left(F_{(1,8)}=3.03 ; p>0.05\right.$; data not shown). Thus, CREB overexpression in the amygdala does not facilitate STM for fear conditioning.

\section{DISCUSSION}

This paper provides the first direct evidence that increasing CREB levels in a defined mammalian brain region enhances

LTM formation. We show that overexpression of CREB in the basolateral complex of the amygdala of rats enhances the formation of LTM after a fear training protocol that normally induces STM but little or no LTM. Furthermore, we show that the effects of CREB overexpression on LTM formation are specific, in terms of biochemistry, anatomy, stimulus processing, time course, and training protocol used. First, the facilitatory effects of CREB in this task depend on phosphorylation at $\operatorname{Ser}^{133}$, because similar overexpression of mCREB, with a single point mutation at this phosphoacceptor site, does not facilitate LTM. Second, the enhancing effects of HSV-CREB on LTM formation showed anatomical specificity to the basolateral amygdala because infusions of HSV-CREB into brain regions surrounding the amygdala or into a control region (the caudate nucleus) failed to enhance LTM formation after massed training. Third, the LTM facilitation produced by overexpression of CREB cannot be attributed to nonspecific effects on US or CS processing. Fourth, the temporal specificity of the effects of CREB overexpression suggests the critical involvement of LTM encoding rather than retrieval processes. Last, overexpression of CREB does not alter STM produced by massed training or LTM produced by spaced training, indicating that overexpression of CREB enhances the formation of LTM only under specific training conditions, such as massed training.

These results show for the first time that overexpression of CREB in a specific mammalian brain region at a specific time enhances LTM. Although many manipulations directly or indirectly produce learning and/or memory deficits, very few manipulations actually increase memory or produce a gain of function (Carew, 1996). Here we show that injection of HSV-CREB into the basolateral complex of the amygdala before massed training produced a predicted facilitation of memory formation. Similarly, previous research using the same HSV-CREB virus shows that infusion of HSV-CREB, but not HSV-mCREB, into the nucleus accumbens increases transcription of a specific target gene containing CRE elements in the promoter region (dynorphin) and decreases the rewarding effects of cocaine (Carlezon et al., 1998). In addition, injection of HSV-CREB increases levels of phosphoCREB in the injected area, whereas injection of HSV-mCREB does not (E. J. Nestler, K. H. Shin, W. A. Carlezon, Jr., C. J. Shi, R. L. Neve, and R. S. Duman, unpublished observation). Previous research estimates that similar infusion with $\mathrm{HSV}$ vectors resulted in $\sim 1000-2000$ transgene-labeled cells $3 \mathrm{~d}$ after viral vector treatment (Carlezon et al., 1997, 1998, 2000). Moreover, although the present infusions of HSV-CREB may not result in observable overexpression of CREB in all neurons near the infusion site, a previous study showed that similar infusion of an $H S V$ vector encoding $\operatorname{pkc} \Delta$ produced overexpression of $\mathrm{pkc} \Delta$ in a small percentage of nigrostriatal neurons, but this was sufficient to produce a robust change in apomorphine-induced rotational behavior (Song et al., 1998). Together, the previous and present data indicate that manipulating levels of a number of transgenes (including CREB) using the HSV system effectively produces robust changes in behavior under certain training conditions.

The present data are consistent with previous research examining the interaction of CREB levels and trial spacing in the formation of LTM. Overexpression of a repressor form of CREB (dCREB2-b) abolishes LTM after spaced training in transgenic flies (Yin et al., 1994), whereas overexpression of an activator form of CREB (dCREB2-a) facilitates the formation of LTM after massed training (Yin et al., 1995). Furthermore, mice with a targeted deletion of two activator isoforms of CREB $\left(\mathrm{CREB}^{\alpha \delta^{\delta-/-}}\right.$ mice) show a 
deficit in LTM after massed training in the water maze, conditioned fear, and social transmission of food preference tasks (Bourtchouladze et al., 1994; Kogan et al., 1996). However, these LTM deficits in $\mathrm{CREB}^{\alpha \delta-1-}$ mice are reversed by spaced training trials (Kogan et al., 1996). Together, these results suggest that CREB may act as a highly conserved gain control device or information filter that governs the kinds of training parameters that will give rise to LTM (Yin et al., 1995; Silva et al., 1998).

Yin et al. (1995) have proposed a model that may account for the interaction of CREB levels and trial spacing in LTM formation. This model suggests that CREB acts as a molecular switch that activates the transcription necessary for LTM formation only when activator isoforms of CREB overcome the blocking effect of repressor isoforms of CREB. The model posits that training induces both the activator and repressor forms of CREB but that the activator forms inactivate more slowly than the repressor forms of CREB. This slower inactivation rate may account for the findings that spaced, but not massed, training produces maximal LTM. The rest intervals between spaced training trials would allow for the accumulation of activator forms of CREB, increase the ratio of the activator to repressor forms, and induce LTM. On the other hand, massed training would not induce LTM because the rapid occurrence of the next training trial would not allow for such an accumulation of activator forms and the activator forms would never outweigh the repressor forms of CREB.

Here we show that increasing CREB expression in the amygdala facilitates LTM formation only after massed training. The present finding that increasing CREB expression in the amygdala did not change the level of LTM after spaced training using either a weak or strong intensity of shock is consistent with this model. It may be that overexpression of CREB in the amygdala increases the ratio of CREB activators to repressors such that, after even a massed training session, the level of activators outweighs the level of repressors, thereby inducing the transcription necessary to produce LTM. However, the balance of activators and repressors during spaced training is normally toward an accumulation of activators such that a further skewing of this balance via CREB overexpression would not further enhance the formation of LTM.

Although CREB originally was identified as a target of the cAMP-PKA signaling pathway, more recent studies have shown that CREB may be directly or indirectly phosphorylated at Ser 133 by $\mathrm{Ca}^{2+} /$ calmoldulin (CaM)-dependent protein kinases (CaMKII and/or CaMKIV) and by mitogen-activated proteinextracellular signal-regulated kinases (MAP kinases or ERKs) (Dash et al., 1991; Sheng et al., 1991; Matthews et al., 1994; Bito et al., 1996; Xing et al., 1996; Impey et al., 1998b; De Cesare et al., 1999; Roberson et al., 1999). Treatments that disrupt function at various points along these pathways upstream of CREB induce deficits in LTM similar to those produced by directly disrupting CREB itself. For instance, overexpression of a dominant negative form of PKA (Abel et al., 1997), as well systemic (Atkins et al., 1998; Selcher et al., 1999), intracerebroventricular (Bourtchouladze et al., 1998; Schafe et al., 1999), or intra-amygdala (Ding et al., 1998; Schafe and LeDoux, 2000) administration of inhibitors of PKA or MAP kinase activity impairs LTM but not STM. Together, these results suggest that CREB may act as a final central switch onto which various signaling pathways convergence to regulate the likelihood of LTM formation.

\section{REFERENCES}

Abel T, Nguyen P, Barad M, Deuel T, Kandel ER, Bourtchouladze R (1997) Genetic demonstration of a role for PKA in the later phase of LTP in hippocampus-based long-term memory. Cell 88:615-626.
Armstrong RC, Montminy MR (1993) Transsynaptic control of gene expression. Annu Rev Neurosci 16:17-29.

Atkins CM, Selcher JC, Petraitis JJ, Trzaskos JM, Sweatt JD (1998) The MAPK cascade is required for mammalian associative learning. Nat Neurosci 1:602-609.

Barela PB (1999) Theoretical mechanisms underlying the trial-spacing effect in Pavlovian fear conditioning. J Exp Psychol Anim Behav Process 25:177-193.

Bartsch D, Casadio A, Karl KA, Serodio P, Kandel ER (1998) CREB1 encodes a nuclear activator, and a cytoplasmic modulator that form a regulatory unit critical for long-term facilitation. Cell 95:211-223.

Bito H, Deisseroth K, Tsien RW (1996) CREB phosphorylation and dephosphorylation: a $\mathrm{Ca}^{2+}$ - and stimulus duration-dependent switch for hippocampal gene expression. Cell 87:1203-1214.

Bourtchouladze R, Frengueli B, Blendy J, Cioffi D, Schutz G, Silva AJ (1994) Deficient long-term memory in mice with a targeted mutation of the cAMP-responsive element binding protein. Cell 79:59-68.

Bourtchouladze R, Abel T, Berman N, Gordon R, Lapidus K, Kandel ER (1998) Different training procedures recruit either one or two critical periods for contextual memory consolidation, each which requires protein synthesis and PKA. Learn Mem 5:365-374.

Campeau S, Davis M (1995) Involvement of the central nucleus and basolateral complex of the amygdala in fear conditioning measured with fear-potentiated startle in rats trained concurrently with auditory and visual conditioned stimuli. J Neurosci 15:2301-2311.

Carew TJ (1996) Molecular enhancement of memory. Neuron 15:5-8.

Carew TJ, Pinsker HM, Kandel ER (1972) Long-term habituation of a defensive withdrawal reflex in Aplysia. Science 175:451-454.

Carlezon Jr WA, Boundy VA, Haile CN, Lane SB, Kalb RG, Neve RL, Nestler EJ (1997) Sensitization to morphine induced by viralmediated gene transfer. Science 277:812-814.

Carlezon Jr WA, Thome J, Olson VG, Lane-Ladd SB, Brokin ES, Hiroi N, Duman RS, Neve RL, Nestler EJ (1998) Role of CREB in cocaine reward. Science 181:2272-2274.

Carlezon Jr WA, Haile CN, Coopersmith R, Hayashi Y, Malinow R, Neve RL, Nestler EJ (2000)

zensDistinct sites of opiate reward and aversion within the midbrain identified using a herpes simplex virus vector expressing GluR1. J Neurosci 20:RC62.

Cassella JV, Davis M (1986) The design and calibration of a startle measurement system. Physiol Behav 36:377-383.

Dash PK, Hochner B, Kandel ER (1990) Injection of the cAMPresponsive element into the nucleus of Aplysia sensory neurons blocks long-term facilitation. Nature 345:718-721.

Dash PK, Karl KA, Colicos MA, Prywes R, Kandel ER (1991) cAMP response element binding protein is activated by $\mathrm{Ca}^{2+} /$ calmoldulin as well as cAMP-dependent protein kinase. Proc Natl Acad Sci USA 88:5061-5065.

Davis HP, Squire LR (1984) Protein synthesis and memory. Psychol Bull 96:518-559.

Davis M (1992) The role of the amygdala in fear and anxiety. Annu Rev Neurosci 15:353-375.

De Cesare D, Fimia GM, Sassone-Corsi P (1999) Signaling routes to CREM and CREB: plasticity in transcriptional activation. Trends Biochem Sci 24:281-285.

Ding C, Lee YL, Davis MD (1998) Role of PKA and CaM kinase in fear conditioning assessed with fear-potentiated startle using local infusion of Rp-8-Br-cAMP, KN-62, or KN-93 into the amygdala. Soc Neurosci Abstr 22:365.

Ebbinghaus H (1885) Uber das Gedachtnis. New York, Dover.

Fanselow MS, Tighe TJ (1988) Contextual conditioning with massed versus distributed unconditional stimuli in the absence of explicit conditional stimuli. J Exp Psychol Anim Behav Process 14:187-199.

Foulkes NS, Borelli E, Sassone-Corsi P (1991) CREM gene: use of alternative DNA-binding domains generates multiple antagonists of cAMP-induced transcription. Cell 64:739-749.

Freudenthal R, Locatelli F, Hermitte G, Maldonado H, Lafourcade C, Romano A (1998) Kappa-B like DNA-binding activity is enhanced after spaced training that induces long-term memory in the crab Chasmagnathus. Neurosci Lett 242:143-146.

Ginty DD, Bading H, Greenberg ME (1992) Trans-synaptic regulation of gene expression. Curr Opin Neurobiol 2:312-316.

Gonzalez GA, Montminy MR (1989) Cyclic AMP stimulates somatostatin gene transcription by phosphorylation of CREB at serine 133. Cell 59:675-680.

Guzowski JF, McGaugh JC (1997) Antisense oligodeoxynucleotidemediated disruption of hippocampal CREB protein levels impairs memory of a spatial task. Proc Natl Acad Sci USA 94:2693-2698.

Impey S, Smith DM, Obrietan K, Donahue R, Wade C, Storm DR (1998a) Stimulation of cAMP element (CREB)-mediated transcription during contextual learning. Nat Neurosci 1:595-601.

Impey S, Obrietan K, Wong ST, Poser S, Yano S, Wayman G, Deloulme JC, Chan G, Storm DR (1998b) Cross talk between ERK and PKA is required for $\mathrm{Ca}^{2+}$ stimulation of CREB-dependent transcription and ERK nuclear translocation. Neuron 21:869-883. 
Kaang BK, Kandel ER, Grant SGN (1993) Activation of cAMPresponsive genes by stimuli that produce long-tem facilitation in Aplysia sensory neurons. Neuron 10:427-435.

Kogan JH, Frankland PW, Blendy JA, Coblentz J, Marowitz A, Schutz G, Silva AJ (1996) Spaced training induces normal long-term memory in CREB mutant mice. Curr Biol 7:1-11.

Lamprecht R, Hazui S, Dudai Y (1997) cAMP response elementbinding protein in the amygdala is required for long- but not short-term conditioned taste aversion memory. J Neurosci 17:8443-8450.

LeDoux JE (2000) Emotion circuits in the brain. Annu Rev Neurosci 23:155-184.

LeDoux JE, Cicchetti P, Xagoraris A, Romanski LM (1990) The lateral amygdaloid nucleus: sensory interface of the amygdala in fear conditioning. J Neurosci 10:1062-1069.

Lim F, Hartley D, Starr P, Lang P, Song S, Yu L, Wang Y, Geller AI (1996) Generation of high-titer defective HSV-1 vectors using an IE 2 deletion mutant and quantitative study of expression in cultured cortical cells. Biotechniques 20:460-469.

Maren S, Fanselow MS (1996) The amygdala and fear conditioning: has the nut been cracked? Neuron 16:237-240.

Matthews RP, Guthrie CR, Wailes LM, Zhao X, Means AR, McKnight GS (1994) Calcium/calmodulin-dependent protein kinase types II and IV differentially regulate CREB-dependent gene expression. Mol Cell Biol 14:6107-6116.

Miserendino MJ, Sananes CB, Melia KR, Davis M (1990) Blocking of acquisition but not expression of conditioned fear-potentiated startle by NMDA antagonists in the amygdala. Nature 345:716-718.

Molina CA, Foulkes NS, Lalli E, Sassone-Corsi P (1993) Inducibility and negative autoregulation of CREM: an alternative promoter directs the expression of ICER, an early response repressor. Cell 75:875-886.

Neve RL, Lim F (1999) Overview of gene delivery into cells using HSV-1-based vectors. In: Current protocols in neuroscience, pp 4.12.14.12.7. New York: Greene and Wiley Interscience.

Neve RL, Howe JR, Hong S, Kalb RG (1997) Introduction of the glutamate receptor subunit 1 into motor neurons in vitro and in vivo using a recombinant herpes simples virus. Neuroscience 79:435-447.

Paxinos G, Watson C (1986) The rat brain in stereotaxic coordinates. Sydney: Academic.

Roberson EE, English JD, Adams JP, Selcher JC, Kondratick C, Sweatt JD (1999) The mitogen-activated protein kinase cascade couples PKA and $\mathrm{PKC}$ to $\mathrm{CAMP}$ response element binding protein phosphorylation in area CA1 of hippocampus. J Neurosci 19:4337-4348.

Romanski LM, Clugnet MC, Bordi F, LeDoux JE (1993) Somatosensory and auditory convergence in the lateral nucleus of the amygdala. Behav Neurosci 107:444-450.

Sassone-Corsi P (1995) Transcription factors responsive to cAMP. Annu Rev Cell Dev Biol 11:355-377.

Schafe GE, LeDoux JE (2000) Memory consolidation of auditory pavlovian fear conditioning requires protein synthesis and protein kinase A in the amygdala. J Neurosci 20:RC96.

Schafe GE, Nadel NV, Sullivan GM, Harris A, LeDoux JE (1999) Memory consolidation for contextual and auditory fear conditioning is dependent on protein synthesis, PKA and MAP kinase. Learn Mem 6:97-110.

Selcher JC, Atkins CM, Trzaskos JM, Paylor R, Sweatt JD (1999) A necessity for MAP kinase activation in mammalian spatial learning. Learn Mem 6:478-490.

Sheng M, Thompson MA, Greenberg ME (1991) CREB: a Ca ${ }^{2+}$ regulated transcription factor phosphorylated by calmodulindependent kinases. Science 252:427-430.

Silva AJ, Kogan JH, Frankland PW, Kida S (1998) CREB and memory. Annu Rev Neurosci 21:127-148.

Song S, Wang Y, Bak SY, During MJ, Bryan J, Ashe O, Ullrey DB, Trask LE, Grant FD, O’Malley KL, Riedel H, Goldstein DS, Neve KA, LaHoste GJ, Marshall JF, Haycock JW, Neve RL, Geller AI (1998) Modulation of rat rotational behavior by direct gene transfer of constitutively active protein kinase $\mathrm{C}$ into nigrostriatal neurons. J Neurosci 18:4119-4132.

Tully T, Preat T, Boynton SC, Del Vecchio M (1994) Genetic dissection of consolidated memory in Drosophila. Cell 79:35-47.

Xing J, Ginty DD, Greenberg ME (1996) Coupling of the RAS-MAPK pathway to gene activation by RSK2, a growth factor-regulated CREB kinase. Science 273:959-963.

Yin JCP, Wallach JS, Del Vecchio M, Wilder EL, Zhou H, Quinn WG, Tully T (1994) Induction of a dominant-negative CREB transgene specifically blocks long-term memory in Drosophila. Cell 79:49-58.

Yin JCP, Del Vecchio M, Zhou H, Tully T (1995) CREB as a memory modulator: induced expression of a dCREB2 activator isoform enhances long-term memory in Drosophila. Cell 81:107-115. 